\title{
Reuna
}

\section{COMPARTILHAMENTO DE SENTIDO AO TRADUZIR OBJETIVOS DA ORGANIZAÇÃO EM SISTEMAS DE INFORMAÇÃO}

\section{MEANING SHARING FOR TRANSLATION OBJECTIVES OF THE ORGANIZATION TO INFORMATION SYSTEMS}

\author{
http://dx.doi.org/10.21714/2179-8834/2018v23n4p83-106
}

\begin{abstract}
Aline Vieira Malanovicz
Universidade Federal do Rio Grande do Sul (UFRGS) e Faculdade Dom Bosco de Porto Alegre, Brasil. E-mail: malanovicz@gmail.com
\end{abstract}

Submissão: 02 Abr. 2018 Publicação: 31 Mai. 2019. Sistema de avaliação: Double blind review.
Centro Universitário UNA, Belo Horizonte - MG, Brasil. Editor geral: Prof. Dr. Gustavo Quiroga Souki

Este artigo encontra-se disponível nos seguintes endereços eletrônicos:

http://revistas.una.br/index.php/reuna/article/view/1064

http://dx.doi.org/10.21714/2179-8834/2018v23n4p83-106

\section{Resumo}

Este trabalho investiga a aproximação da teoria de Karl Weick sobre a organização como definida por seus processos de formação (criação, seleção e retenção) e o tema do (des)alinhamento de sentidos no compartilhamento da informação e do conhecimento dos objetivos da organização. É enfocado o percurso desse compartilhamento de informações na tradução dos objetivos, desde os níveis estratégicos até seus desdobramentos gerenciais, operacionais e tecnológicos, concretizados na implantação de sistemas de informação. Esse desenvolvimento depende imensamente da interação entre usuários e analistas de sistemas, pois no núcleo do processo está a necessidade de criar um entendimento compartilhado entre o usuário e o analista. Otema é explorado em um ensaio teórico que busca estabelecer as possíveis relações entre ocorpo teórico como lente explicativa para observação e o objeto de observação, que consiste no processo de traduçãodos objetivos organizacionais, tratados como informações a serem compartilhadas

Palavras-chave: Modelo de Organização como Processo; Entendimento Compartilhado entre Usuários e Desenvolvedores; Desenvolvimento de Sistemas; Ensaio Teórico. 


\section{ABSTRACT}

This paper investigates the approach of Karl Weick's theory of organization as defined by their formation processes (creation, selection and retention) and the issue of (dis)alignment on sharing information and knowledge about organization's goals. It focused on the route of this information: sharing in the translation of the objectives from the strategic level to its managerial, operational and technological developments, until achieves the implementation of information systems. This development depends greatly on the interaction between users and systems analysts. The core process lays on the need to create a shared understanding between the user and the analyst. This theme is explored in a theoretical essay that establish potential links between the theoretical framework as an explanatory lens for observation and the observation object, which is the process of translating organizational objectives, treated as information to be shared.

Keywords: Organizing Model; Shared Understanding between Users and Developers; Systems Development; Theoretical essay.

\section{Introdução}

Pesquisas recentes em diferentes áreas da gestão apontam uma variedade de dificuldades enfrentadas pelas organizações no processo de comunicação de objetivos, especialmente no contexto de projetos, que são parte inerente da implementação de estratégias (SCHLEGEL, McLEOD, SELFRIDGE, 2018). Exemplos que podem ser citados são os trabalhos de Liebel, Tichy, Knauss, Ljungkrantz e Stieglbauer (2018), Vanhanem, Lehtinen e Lassenius (2018), análises da realidade brasileira como Cobaito (2018) e Cyganczuk, Mendes, e Pécora (2018).

Como lembra Belth (1971, p.22), "a teoria é indispensável para dar significado aos fatos investigados que, de outra maneira, não teriam sentido algum; ela explica os aspectos da realidade em estudo, e permite uma interpretação dos fatos observados, o que oferece abertura de perspectivas para futuras pesquisas". Com tal intenção se inicia esta argumentação, a exemplo da pesquisa teórica de Bjorvatn e Wald (2018). O tema a ser explorado neste trabalho refere-se ao processo de (des)alinhamento na produção e compartilhamento (criação, seleção e retenção) de sentidos na tradução dos objetivos estratégicos pelos níveis da organização até sua implantação em sistemas de informação.

No passado (WERNHAM, 1985), havia uma crença ingênua na literatura tradicional sobre estratégia, um pressuposto de que um plano estratégico, depois de estabelecido, se difundia pela organização, e todas as pessoas tinham o mesmo entendimento e a mesma percepção da alta gerência sobre a melhor forma de sua execução. Entretanto, estudos apontam a dificuldade das organizações em atingir os objetivos almejados, por exemplo, maturidade da gestão de projetos (ANANTATMULA, RAD, 2018) e implementação de projetos (SCHLEGEL, McLEOD, SELFRIDGE, 2018). A relevância da efetiva implantação se deve ao fato de que, por ao menos dez fatores diferentes (ANTONY, GUPTA, 2018), nem sempre um objetivo de mudar aestratégia de uma empresa se transforma em uma mudança real. 
Também na fase de implementar a estratégia por meio do uso de sistemas de informação para automatização de tarefas operacionais, existem muitos problemas, principalmente associados ao desenvolvimento de sistemas de informação (LIEBEL et al., 2018; SMALLA e WAINWRIGHT, 2018; VANHANEM et al., 2018). O sucesso no desenvolvimento de sistemas de informação depende da relação entre usuários e analistas de sistemas, pois no centro do processo está a necessidade de haver entre eles entendimento compartilhado (MALANOVICZ, BRODBECK, 2017). Nesse contexto, essa melhoria é dos principais interesses da indústria de desenvolvimento de sistemas de informação (CYGANCZUK, MENDES, PÉCORA, 2018).

Os objetivos organizacionais são aqui tratados no sentido em que são abordados e classificados por Miles e colegas (1978) e Rummler e Brache (1994). Rummler e Brache (1994, p.24) os classificam em níveis: objetivos de organização, de processo e de trabalho/executor e conceituam os objetivos como a informação que, em cada nível de desempenho da organização, "especifica cada um dos padrões que refletem as expectativas do cliente quanto à qualidade, quantidade, disponibilidade e custo de cada produto ou serviço". A preocupação da organização é, a exemplo do que mostra a pesquisa de Anantatmula e Rad (2018), quanto a alcançar seus objetivos e as expectativas de qualidade.Miles e colegas (1978) fizeram a proposta original de que os objetivos visam resolver problemas de três diferentes níveis na organização. Para eles, um objetivo empresarial visa resolver um problema tratado em nível institucional da empresa, por exemplo, a escolha do domínio produto/mercado da empresa. Um objetivo administrativo visa resolver um problema administrativo, relacionado com a estrutura e processos organizacionais, por exemplo, racionalização e estruturação, ou a adoção de novas rotinas em parcerias (BYGBALLE, SWARD, 2018). Um objetivo operacional visa resolver um problema operacional ou um problema de engenharia, por exemplo, a escolha das tecnologias para produção e distribuição, ou a arquitetura dos sistemas de informação.

O contexto de pesquisa a ser investigado é representado pela trajetória dos objetivos organizacionais, ao serem traduzidos desde os níveis mais estratégicos até os níveis mais operacionais na organização. Pretende-se investigar qual a contribuição que o modelo teórico de organização de Weick (1973) pode oferecer quando utilizado como lente teórica para observar e compreender este contexto de pesquisa. Como será explicado nas seções seguintes, o modelo de Weick propõe que a organização pode ser definida pelos seus processos de formação, que incluem processos de criação, seleção e retenção das informações que são transmitidas a indivíduos ou grupos na organização. O compartilhamento de sentidos refere-se à compreensão mútua, à tradução fiel, ao entendimento compartilhado entre as pessoas, sobre as informações utilizadas para expressar os objetivos da organização nos seus diferentes níveis.

Para justificar a escolha do tema e a relevância da pesquisa, vale lembrar que diversos aspectos relativos ao assunto já foram investigados e têm sido relatados na literatura como sendo áreas de grande interesse das organizações. Como exemplos, podem ser citados estudos sobre implantação de estratégias, modelagem de processos de negócio, análise de requisitos de sistemas de informação, além do alinhamento estratégico e as dificuldades para estabelecê-lo entre tais aspectos. Também são discutidas aplicações do modelo de Weick a aspectos da dinâmica organizacional como a interpretação do ambiente, a tomada de decisões e o processo de organizar. 


\section{Abordagens ao tema da comunicação de objetivos na organização}

Quanto à implantação de estratégias, uma breve revisão da literatura aponta o descompasso entre a formulação da estratégia e a sua implantação efetiva no negócio. Percebe-se, nos estudos, a complexidade do processo de implantação de estratégias (OSWALD et al., 2019; BJORVATN e WALD, 2018; HREBINIAK, 2013), e certa crença em que a organização como um todo compartilhe o entendimento do plano estratégico. Como tentativas de explicação da baixa capacidade de implantação da estratégia nas organizações, alguns fatores envolvem a clareza em relação aos objetivos; a comunicação desses objetivos; e o envolvimento de pessoas-chave na formulação e implantação (HREBINIAK, 2013).

Quanto ao alinhamento estratégico entre processos de negócio e tecnologia de informação, Tonolli Júnior (2012) apresenta uma breve revisão de literatura, mostrando que o alinhamento estratégico, definido como a adequação estratégica e integração funcional entre estratégias de negócio e estratégias de tecnologia de informação, Integra processos críticos denegócio através da sua adequação aos mercados e produtos e às competências centrais da organização, buscando agregar valor e vantagem competitiva como ferramenta estratégica (BRODBECK e HOPPEN, 2003). Percebe-se que só é atingido quando o foco de negócio é definido, o que permite uma comunicação mais coerente e melhores definições de projetos (JIANG, KLEIN e FERNANDEZ, 2018), já que as lacunas (gaps) entre os diferentes níveis de abstração dos objetivos levam a inconsistências (LIEBEL et al., 2018).

Quanto à comunicação de objetivos no contexto de projetos, pesquisas mostram-na integrando as chamadas soft skills como fator chave de sucesso (ZUO et al., 2018; GARCIA-CARBONELL et al., 2018), destacando-se a ênfase dada a ela no uso de métodos ágeis para desenvolvimento de sistemas (STERREN e GOLDING, 2018; NOGUERA, GUERRERO-ROLDÁN, MASÓ, 2018), a influência dos stakeholders (NAHYAN et al., 2019; OLIVEIRA e RABECHINI, 2019) e os diferentes tipos de comportamentos comunicativos (MANATA et al., 2018).

Quanto à modelagem de processos de negócio, Ghalimi (2007) apresenta uma breve revisão da literatura acadêmica, que também tem demonstrado que muitas organizações não têm claramente seus processos mapeados e, quando os têm, eles não se encontram alinhados às suas estratégias (DEBEVOISE, 2007; GONÇALVES, 2000). Metodologias e Tecnologias de Informação que utilizam conceitos como BPM (Business Process Management) e SOA (Service Oriented Architecture) buscam sanar esta lacuna através do conceito de processos de negócio orientados para serviços, visando à fiel tradução dos processos de negócio para os sistemas de automação e melhoria pelo monitoramento dos processos, com ganhos e vantagens competitivas para as organizações (DEBEVOISE, 2007; WEILL e ROOS, 2005).

Quanto ao levantamento e análise de requisitos de sistemas de informação, uma breve revisão da literatura aponta o descompasso na comunicação entre usuários e analistas nessa fase, definida como o momento em que o analista de sistemas tenta entender as necessidades dos usuários e da organização, e o conceito do usuário para um sistema particular (MALANOVICZ e BRODBECK, 2017). A revisão cita trabalhos que afirmam que uma comunicação pobre ou propensa a erros entre o usuário e o analista ainda é um dos principais problemas, especificamente quanto à criação de um entendimento compartilhado entre usuário e analista (MALANOVICZ e 
BRODBECK, 2017). O problema continua atual, como mostram pesquisas em busca de melhores definições de requisitos para maior sucesso das implementações de projetos (SMALLA e WAINWRIGHT, 2018; LIEBEL et al., 2018), inclusive com análises do uso de mídias sociais (PIVEC e MACEK, 2019).

Quanto às aplicações dos modelos de Weick, a revista Organization Studies (2006) dedica uma edição à obra do mestre, "amplamente considerado como um dos pensadores mais influentes nos estudos organizacionais" (p.1574). Seu trabalho mais influente é inegavelmente "The Social Psychology of Organizing" (primeira edição em 1969, segunda em 1979, em português em 1973), conforme Anderson (2006), que analisa detalhadamente a frequência de citações dessa obra. Ramos-Rodriguez e Ruiz-Navarro (2004) a apontam como a 24‥ obra mais citada em artigos do Strategic Management Journal entre 1980 e 2000. Pesquisas mais recentes baseadas no modelo exploram temas tais como resiliência organizacional (ISHAK e WILLIAMS, 2018) e a criação de conhecimento intersubjetivo em redes de serviços (PERONARD e BRIX, 2018).

Os assuntos acima descritos já foram amplamente descritos na literatura, com vários deles já relacionados entre si. No entanto, não foi encontrada na literatura a relação entre o modelo de Weick de organização como processo de criação-seleçãoretenção de Informação e Ambiguidade e o contexto do alinhamento dos objetivos estratégicos, processos de negócio e sistemas de informação. Sendo assim, constatam-se aí possíveis lacunas que podem ser exploradas para uma contribuição teórica, o que leva à proposta da seguinte questão de pesquisa:

No contexto do alinhamento dos objetivos estratégicos, processos de negócio e sistemas de informação, qual é a contribuição que as ideias de Weick sobre processos de criação-seleção-retenção de informações na produção de sentido compartilhado podem trazer para a compreensão do processo de tradução de objetivos estratégicos, táticos, operacionais, tecnológicos no caminho percorrido pela informação desde o estrategista até o analista de sistemas numa organização?

O conjunto teórico de referência para esta argumentação é aquele proposto por Karl Weick na obra "The Social Psychology of Organizing" (1973). Portanto, o posicionamento teórico-epistemológico deste trabalho frente ao objeto de pesquisa segue a opção do autor. "O interpretativismo de Weick é positivista e sistêmico" (ANDERSON, 2006). Conceitos dessa teoria oferecem suporte ao modelo, que enfatiza as relações subjetivas no processo de organização.

\section{O modelo para o estudo da organização proposto por Weick}

Pode-se dizer que modelos que apresentam a organização como uma estrutura estática se mostram limitados na tentativa de compreensão das organizações, ao "deixar de lado aspectos fundamentais do estudo dos complexos sistemas organizacionais, como as interações dinâmicas que neles se estabelecem, e dimensões mutáveis, dinâmicas, ambíguas ou inexatas" (DAFT e WEICK, 2005). Por isso, ao argumentar sobre a abordagem da organização como processo, em "A Psicologia Social da Organização" (1973), Karl Weick propõe "um modelo para o estudo da organização" (p.90), que pode ser considerado "uma abstração que conserva, em forma econômica, quase todos os aspectos que explicamos, uma 
'recordação' das teses fundamentais do livro" (p.95); "uma resenha dos aspectos básicos da organização" (p.90):

A organização é fluida, em mudança contínua, continuamente com a necessidade de reformulação, e parece ser uma entidade apenas quando essa fluidez é "congelada" em certo momento no tempo. Isso significa que precisamos definir a organização através do processo de sua formação (WEICK, 1973, p.91)

As discussões anteriores sugerem que uma organização pode ser definida através dos processos de sua formação. A tese central é que qualquer organização é a maneira pela qual passa pelos processos de sua formação. Tais processos consistem de comportamentos interligados, estão relacionados e constituem um sistema (WEICK, 1973, p.90)

As relações de mútua causação, que colocam os processos separados num sistema, constituem os controles do sistema. Isso significa que, de acordo com o padrão de relações que existe entre os processos, haverá controle ou caos. Deve-se lembrar que são as relações, mais do que os sistemas, que controlam o destino de qualquer sistema. Se considerarmos tais propriedades como aspectos básicos, encontrados em qualquer organização, de qualquer tamanho, e que fazem o que quer que seja, é possível oferecer uma definição formal de organização (WEICK, 1973, p.90).

A Figura 1 resume graficamente as relações hipotéticas em um processo, bem como entre os processos de criação, seleção e retenção. "Há dois tipos de informação para o processo de criação a partir do qual se forma esse ambiente: informações de dentro do sistema (a linha de retenção à criação) e informações de fora do sistema (a linha da mudança ecológica à criação)" (p.95). Para representar como os processos de organização são interligados, Weick (1973) utiliza a notação "sistêmica" para relações de influência: diretas (+) (aumento de uma causa aumento na outra; idem quanto à redução); e inversas (-) (aumento de uma causa redução na outra, e viceversa) (p.81). Tais aspectos serão explicados nas seções seguintes.

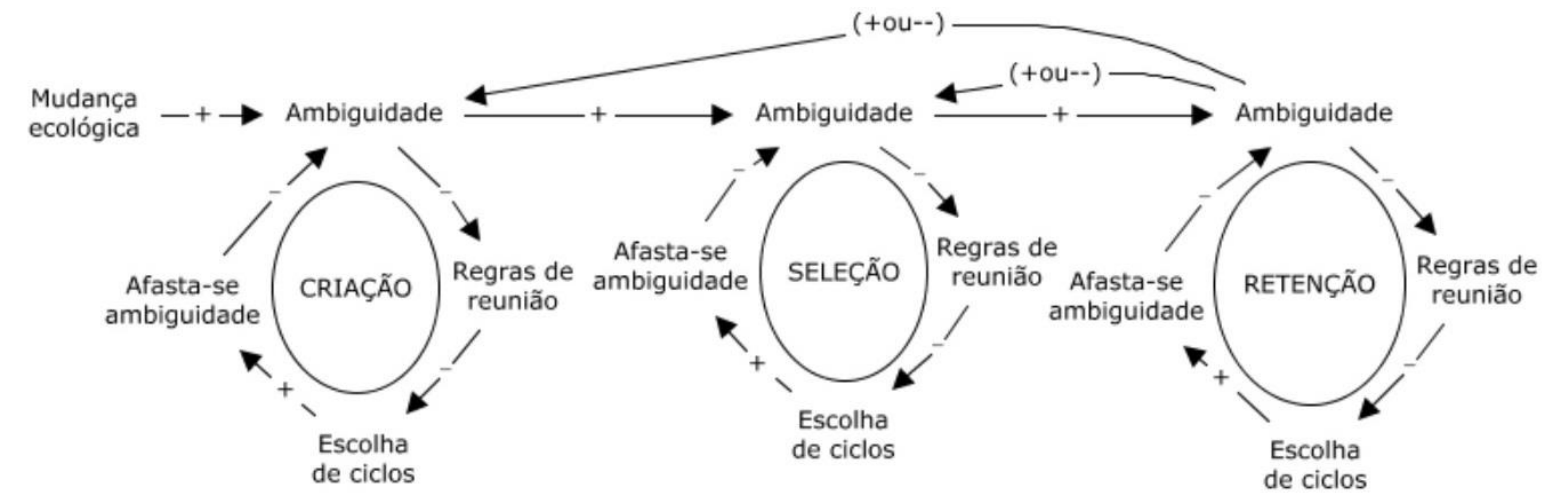

Figura 1. O modelo de formação da organização (Fonte: WEICK, 1973, p.93) 
Vale lembrar que "o modelo serve como um guia para pessoas que desejam observar organizações. [...] Uma vez que o observador especifique os elementos e as relações, pode verificar, refinar e até refutar as ideias aqui mencionadas" (WEICK, 1973, p.95).

\subsection{A ambiguidade da informação conforme o modelo proposto por Weick}

Para Weick (1973, p.91), "O ambiente de informação em que os processos de organização atuam é criado com base em interpretações retrospectivas de ações já completadas feitas pelos participantes das organizações. Os atores separam partes de um contínuo de experiência em experiências discretas, o que produz a matériaprima da formação da organização, e gera excesso de ambiguidade no sistema" [...] "O processo de formação da organização consiste na solução da ambiguidade nesse ambiente criado através de comportamentos interligados e incluídos em processos condicionalmente relacionados. [...] A formação da organização procura, de modo geral, processar a informação, e especificamente, reduzir a ambiguidade de informações recebidas" (WEICK, 1973, p.91).

Para reduzir essa ambiguidade das informações recebidas, é preciso "que a ambiguidade seja antes registrada e depois afastada. [...] A fim de registrar a ambiguidade, as regras usadas para compor o processo de criação-seleção-retenção registram a ambiguidade; e a fim de afastar a ambiguidade, os ciclos do processo de criação-seleção-retenção aplicados à informação recebida afastam a ambiguidade. [...] De fato, cada ciclo comportamental interligado tem potencial para afastar certa ambiguidade, mas é apenas quando vários ciclos diferentes são aplicados à informação que um grau suficiente de certeza é conseguido para que seja possível ação não ambígua" (WEICK, 1973, p.91).

"Esses ciclos comportamentais interligados estão incluídos em três processos separados", como foi apresentado na Figura 1. "Esses três processos estão interrelacionados e constituem um sistema".

O processo de criação gera a informação a que o sistema se adapta, e ao fazer isso afasta uma pequena parte de ambiguidade (menos do que a afastada pelos outros dois processos).

O processo de seleção, a partir de critérios estabelecidos pela experiência passada, separa a diversidade presente na informação ambígua, admite as partes que satisfazem os critérios e assim coloca a informação ainda ambígua numa forma pelo menos ordenada.

O processo de retenção também reduz parte da ambiguidade, integrando itens novos em itens anteriormente conservados. [...] A reorganização interna da informação dentro do sistema de retenção afasta a ambiguidade criada por contradições. (WEICK, 1973, p.92)

Pode-se dizer que esses ciclos de comportamentos interligados são os elementos básicos dos processos que constituem qualquer organização. 
São formados por comportamentos repetitivos, recíprocos e contingentes, que se desenvolvem e são mantidos entre dois ou mais atores. [...] Supõe-se que a redução da ambiguidade seja uma atividade coletiva, uma atividade realizada por conjuntos de atores que interligam diferentes conjuntos de comportamentos (WEICK, 1973, p.91).

"As relações básicas entre os processos representam as formas pelas quais os processos são determinados pelo estado das informações recebidas" (WEICK, 1973, p.92). A Figura 1, apresentada anteriormente, mostra também setas entre processos e indica, além dos relacionamentos entre os processos, que "o grau de ambiguidade no ponto de partida da seta determina o grau de ambiguidade que existirá, como informação ao processo, no ponto de chegada da seta. De modo geral, tais relações são ligações causais diretas. [...] Isso significa que no processo será criado o mesmo grau de ambiguidade existente na informação recebida."

- Quando existe muita ambiguidade, haverá menos regras para composição do processo.

- Quando existe pouca ambiguidade, aumenta o número de regras.

- As regras, por sua vez, determinam o número de ciclos comportamentais de criação-seleção-retenção interligados que serão reunidos para o afastamento efetivo de ambiguidade: quanto menos ciclos de criação-seleção-retenção, mais ciclos escolhidos.

Nos casos de retenção para seleção e retenção para criação, essas relações podem ser de influência direta (+) ou inversa (-). "Isso depende das decisões dos atores no sistema" (WEICK, 1973, p.94).

\section{O caminho dos objetivos pelos níveis da organização}

A exposição aqui definida sobre o caminho dos objetivos pelos níveis da organização aborda os objetivos organizacionais primordialmente como informações. Entende-se que exista, ou deva existir, nas organizações, uma tradução entre a informação que compõe os objetivos organizacionais definidos pelos estrategistas (informação gerada no início do "caminho"), e a informação que vai ser transformada, no fim desse caminho, em funcionalidades implementadas em um sistema de informações da organização. Entende-se que a tradução dessa informação deve ser fiel, e que o sentido da informação deve ser compartilhado, para que não haja controvérsias entre os objetivos definidos.

Vale recordar que Rummler e Brache (1994) descrevem o funcionamento das organizações, estabelecendo três níveis organizacionais: Organização, Processo e Trabalho/Executor, com base na proposta de Miles e colegas (1978) de níveis Institucional, Intermediário e Operacional, que lidam, respectivamente, com problemas empresariais, administrativos (de estrutura e processos organizacionais), e operacionais (que englobam também aspectos tecnológicos). Esta exposição os reorganiza em quatro níveis, incluindo-se um nível tecnológico separado do nível operacional: 
- Nível Estratégico: os executivos atuam no relacionamento com o ambiente;

- Nível Tático: os gerentes organizam, dirigem, controlam o fluxo do trabalho;

- Nível Operacional: os funcionários e operadores efetuam a lida operacional;

- Nível Tecnológico: os desenvolvedores de software ou analistas de sistemas implantam em Sistemas de Informação automatizações de tarefas operacionais.

É a estratégia, segundo Hrebiniak (2013), que define os objetivos e as metas que devem ser alcançados pela organização, a missão e valores a serem perseguidos, e define a direção básica da empresa. Assim, pode-se dizer que um ou mais executivos determinam os objetivos estratégicos da organização, e esses objetivos estratégicos consideram aspectos de relacionamento com o ambiente organizacional: mercado, clientes, fornecedores, concorrentes, pontos fortes e fracos da organização.

Com base na definição já clássica de Gonçalves (2000), de que uma organização funciona por meio de processos de negócio, pode-se apresentar, como faz Hrebiniak (2013), o planejamento estratégico de uma organização como sendo composto pelo desdobramento dos objetivos estratégicos em planos operacionais. Pode-se então dizer que os objetivos estratégicos são implementados na organização por meio de macroprocessos de negócio. Assim, estes são formados pela interação de processos e subprocessos táticos, idealmente direcionados para determinados objetivos táticos (como eficiência e integração de processos interfuncionais) e são implementados por processos e subprocessos operacionais, também idealmente direcionados para determinados objetivos operacionais (tais como eficiência, controle, exatidão e confiabilidade na realização das tarefas).

Para Debevoise (2007), o uso da automação no fluxo de trabalho pode aumentar a confiabilidade e melhorar o controle e monitoramento dos processos. Assim, alguns objetivos operacionais podem ser atingidos por meio de automação de atividades operacionais. Para o autor, essa automação pode ser implementada nas tecnologias e sistemas de informações definidos pela interação entre usuários gestores do processo e analistas de sistemas na fase de levantar requisitos.

Partindo de tais pressupostos sobre a dinâmica desse processo de tradução de objetivos, pode-se representá-la, identificando atores, objetivos e o fluxo da informação (tradução de objetivos) que flui nesse processo. Os seguintes aspectos referentes ao caminho da informação na organização são mapeados na Figura 2, ilustrando sucintamente a dinâmica do processo descrito.

- Níveis: estratégico, tático, operacional, tecnológico.

- Atores: estrategistas, gerentes, operadores, desenvolvedores de sistemas.

- Objetivos: estratégicos, táticos, operacionais, tecnológicos.

- Traduções: estratégico-tático, tático-operacional, operacional-tecnológico. 


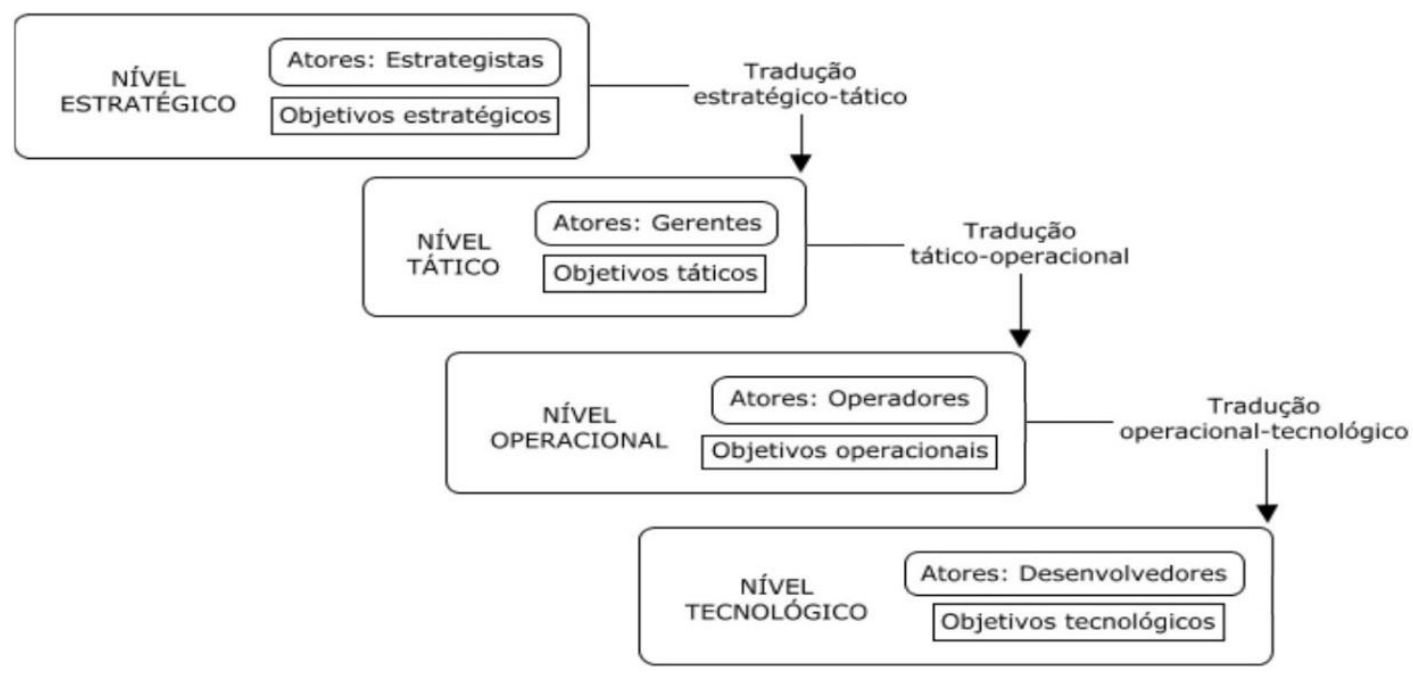

Figura 2. Caminho dos objetivos na organização. Fonte: adaptada de Rummler e Brache (1994).

Pode-se dizer que ocorre um grande processo de tradução dos objetivos estratégicos em objetivos e processos táticos; destes em objetivos e processos operacionais; e destes, por sua vez, em objetivos e processos tecnológicos, implementados em sistemas de informação. Uma necessidade da organização, por questões de coerência, é de que os processos implementados em computador espelhem os objetivos operacionais, que por sua vez devem espelhar os objetivos táticos, que por sua vez, finalizando uma cadeia de traduções fiéis, devem espelhar os objetivos estratégicos originais definidos para a organização. Em outras palavras, convém que exista alinhamento entre estratégia organizacional, processos de negócio, e tecnologia da informação.

Para Jiang, Klein e Fernandez (2018), o melhor alinhamento dos processos com os direcionadores do negócio (como a missão, visão e estratégias organizacionais), ou seja, o alinhamento estratégico, é desejável em uma organização, e é favorecido pelo foco no negócio, que leva a uma comunicação mais coerente. Nesse sentido, metodologias já clássicas como Business Process Management, Gerenciamento de Processos de Negócio, têm como objetivo o alinhamento dos processos de negócios com a estratégia, os objetivos e a cadeia de valor das empresas (ADESOLA, 2005).

Existem também métodos, técnicas e ferramentas para desenvolvimento de sistemas de informação que utilizam diagramas (como a notação BPMN e a família de notações IDEF, por exemplo) para representação formal dos processos e objetivos estratégicos, táticos, operacionais e tecnológicos (implementados em sistemas), para assegurar essa coerência (GHALIMI, 2007). Essas técnicas oferecem meios de que a implantação em sistema espelhe a execução dos processos, tendo como consequência a geração de código programável coerente com os objetivos e processos assim representados. Também o modelo SOA (Service Oriented Architecture - DEBEVOISE, 2007) para construção de sistemas de informação procura representar a organização em camadas de serviços. 
Em outras palavras, mecanismos como esses visam a auxiliar uma tradução fiel, uma compreensão mútua, uma produção de sentido compartilhado dos objetivos da organização. Ou seja, pode-se dizer que o sentido produzido pelo programador ao codificar instruções em um sistema de informação deve ter, em última análise, um objetivo amplo em comum com o sentido produzido pelo estrategista ao definir os objetivos estratégicos da organização como um todo.

\subsection{A ambiguidade no caminho dos objetivos pela organização}

Retomando a exposição referente ao caminho dos objetivos pelos níveis da organização, procura-se aqui incluir na descrição da dinâmica desse processo a existência de ambiguidade nessa informação.

Pode-se dizer que, no processo anteriormente descrito de formulação e tradução de objetivos estratégicos para táticos, seguido dos operacionais e culminando nos objetivos tecnológicos, existe potencial para ocorrência de ambiguidade na informação produzida, transmitida e recebida. Consequentemente, ocorrem perdas de informação na tradução dos objetivos. A seguir é esboçado um relato do caminho dos objetivos e da ambiguidade potencial das informações no processo de tradução.

- Os propositores originais das ideias (os estrategistas) formulam e enunciam os objetivos estratégicos da organização para o grupo de gestores táticos. Caso o enunciado não seja formal o suficiente para não permitir dúvidas da parte dos receptores da mensagem (o que é humanamente impossível), passa a existir ambiguidade.

- Essa existência de ambiguidade na informação sobre os objetivos exigiria consultas aos formuladores originais do anúncio para o esclarecimento do sentido dos aspectos que ficaram ambíguos. O processo de consultas interativas é uma atitude que tem potencial de contribuir para a produção de sentido compartilhado entre um emissor e um receptor.

- Mas esse entendimento mútuo nem sempre ocorre, pois as ambiguidades podem ser "solucionadas" por uma escolha de suposições que ajudam o gestor tático a produzir para si mesmo o sentido das diretrizes originais. Essas suposições partem da experiência e da compreensão dos objetivos por parte somente do receptor, quando não há a "retroconsulta".

- Quando estes gestores táticos procuram traduzir os objetivos estratégicos em objetivos táticos e anunciam-nos, digamos, ao seu corpo de supervisores operacionais, produzem o sentido desse anúncio de maneira não-consciente, selecionando, retendo e criando aspectos conforme o seu próprio entendimento. Nessa fase da tradução, existe potencial para uma transmissão de objetivos com perda - ou alteração - de informação.

- E assim sucessivamente, existe potencial para ir ocorrendo um processo não consciente de ambiguação, do estrategista para o gestor tático, do gestor tático para o supervisor operacional, do supervisor operacional para os seus funcionários e analistas de sistemas, e do analista de sistemas até a efetiva implantação.

- Essa perda de informação entre as etapas de tradução pode provocar uma discordância entre os objetivos estratégicos e as práticas efetivamente implementadas. O processo é chamado popularmente de "telefone-sem-fio" e é 
ilustrado com bom humor na Figura 3 e na Figura 4, apresentadas na próxima seção.

- Essa ambiguação pode inclusive provocar que atividades operacionais realizadas pelos atores ou por sistemas de informação contrariem os objetivos estratégicos organizacionais definidos.

- A "retroconsulta" ao formulador original, com referência ao objetivo a ser retransmitido, para o esclarecimento do sentido dos aspectos que ficaram ambíguos, pode ser considerada uma "boa prática" com potencial para resolver essa ambiguidade em qualquer fase da tradução, evitando ou minorando a discordância entre a informação recebida e a transmitida.

- Em outras palavras, o ideal é que ocorra a tradução fiel, o entendimento mútuo, a produção de sentido compartilhado: o sentido produzido pelo analista de sistemas ao instruir o sistema de computação deve ter um objetivo amplo em comum com o sentido produzido pelo estrategista ao definir o objetivo estratégico para a organização como um todo.

Quanto à dinâmica de funcionamento da organização no caminho percorrido pelos objetivos, tendo estabelecido a compreensão descrita sobre os processos efetivados pelos atores nessa tradução, a potencial existência de ambiguidade na informação ajuda a destacar a importância do alinhamento.

\subsection{Ilustração da ambiguidade no caminho dos objetivos pela organização}

Para ilustrar a argumentação sobre as ambiguidades que existem nas informações envolvidas na tradução de objetivos, são apresentados a seguir (Figura 3 e Figura 4) dois exemplos bem-humorados, e talvez bem conhecidos, de situações que podem ocorrer nas organizações:

O Quadro 1 apresenta uma distorção na comunicação (no caso, interhierárquica) em que a possível incompreensão de partes das mensagens gera ambiguidades que o retransmissor (tradutor) da informação preenche com suas próprias suposições, causando diferença entre objetivo e efetivação.

Quadro 1. Distorção na Comunicação Inter-hierárquica

De: Diretor Presidente - Para: Gerente

Na próxima sexta-feira, aproximadamente às 17 horas, o cometa Halley estará nesta área. Trata-se de um evento que ocorre a cada 76 anos. Assim, por favor, reúnam os funcionários no pátio da Fábrica, usando capacete de segurança, quando explicarei o fenômeno a eles. Se estiver chovendo, não poderemos ver o raro espetáculo a olho nu, sendo assim, todos deverão se dirigir ao refeitório, onde será exibido um filme "Documentário sobre o Cometa Halley".
De: Chefe de Produção - Para: Mestre $\mathrm{Na}$ sexta-feira às 17 horas, o Diretor pela primeira vez em 76 anos, vai aparecer nu no refeitório da Fábrica, para filmar o Halley, o cientista famoso e sua equipe. Todo mundo deve estar lá de capacete, pois vai ser apresentado um show sobre a segurança na chuva. O diretor levará a banda para o pátio da Fábrica. 
Quadro 1. Distorção na Comunicação Inter-hierárquica (continuação)

De: Gerente - Para: Supervisor

Por ordem do Diretor-Presidente, na sexta-feira às 17 horas, o cometa Halley vai aparecer sobre a Fábrica, a olho nu. Se chover, por favor, reúnam os funcionários, todos com capacete de segurança e os encaminhem ao refeitório, onde 0 raro fenômeno terá lugar, o que acontece a cada 76 anos.

De: Supervisor - Para: Chefe de Produção A convite do nosso querido Diretor, o cientista Halley, 76 anos vai aparecer nu às 17 horas no refeitório da Fábrica, usando capacete, pois vai ser apresentado um filme sobre o raro problema da chuva na segurança. $O$ diretor levará a demonstração para o pátio da Fábrica.
De: Mestre - Para: Funcionários

Todo mundo nu, sem exceção, deve estar com os seguranças no pátio da Fábrica na próxima sexta-feira, às 17 horas, pois o Sr. Diretor e o Sr. Halley, guitarrista famoso, estarão lá para mostrar o raro filme "Dançando na Chuva". Caso comece a chover mesmo, é para ir pro refeitório de capacete na mesma hora. O show ocorre a cada 76 anos.

AVISO GERAL

Na sexta-feira o chefe da Diretoria vai fazer 76 anos e liberou geral pra festa às 17 horas, no refeitório. Vão estar lá, pago pelo mandachuva, Bill Halley e seus cometas. Todo mundo deve estar nu e de capacete, porque a banda é muito louca e o rock vai rolar até o pátio, mesmo com chuva.

Fonte: adaptado de MEDEIROS, 2016.

A Figura 3 apresenta diversas etapas do desenvolvimento de sistemas ao longo das quais ambiguidades e incompreensões podem ocorrer na tradução dos objetivos, sendo preenchidas pelas suposições dos transmissores das informações, e causando divergência entre objetivo e efetivação.

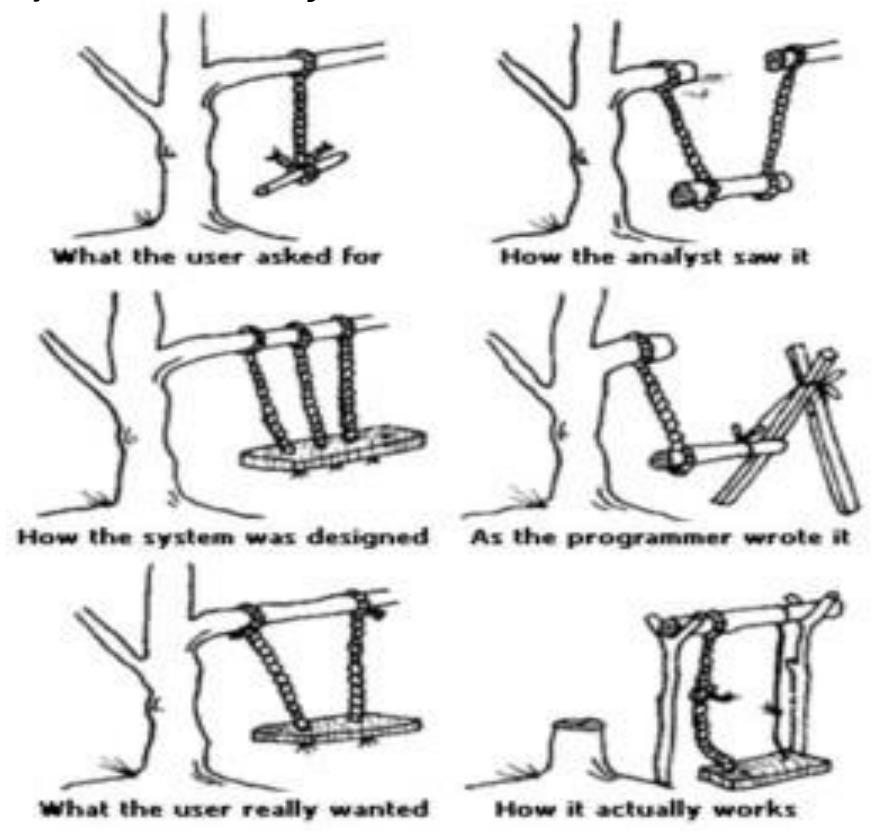

Figura 3. Etapas do Desenvolvimento de Sistemas (Fonte: DONESTES, 2015) 


\section{Aproximação do modelo de Weick ao contexto de pesquisa}

No entender de Weick (1973), as organizações podem ser descritas como sistemas abertos. Essa concepção sistêmica da organização se concilia com a ideia de organização como processo: "uma organização pode ser definida por seus processos de formação: os comportamentos interligados e relacionados que constituem um sistema" (WEICK, 1973, p.90).

A partir desses pressupostos sobre como funciona a organização, elabora-se a argumentação para, inicialmente, aproximar e, se viável, aplicar o modelo de Weick à dinâmica da tradução de objetivos, dentro do contexto do alinhamento entre a estratégia organizacional, os processos de negócio e a implantação em sistemas de informação (alinhamento estratégico). Pode-se dizer que o modelo de Weick (1973) oferece um conjunto teórico que talvez possa explicar o processo de ambiguação na tradução de objetivos estratégicos, táticos, operacionais e tecnológicos, e o processo de desambiguação que se faz necessário para se atingir o alinhamento.

"Dado seu nível de abstração, o modelo tem potencial de ser aplicado a unidades de todos os tipos, mas detalhes importantes variam de acordo com a unidade escolhida. [...] Por exemplo, falamos a respeito de processos, e não a respeito de departamentos ou pessoas. Os três processos podem ser realizados por uma dupla; cada processo poderia ser realizado por um departamento separado; todos poderiam ser realizados em cada um dos departamentos. O padrão de distribuição específica indiscutivelmente influirá na forma de atuação do sistema". (WEICK, 1973, p.96)

A argumentação aqui elaborada procura aproximar o modelo ao contexto do problema em estudo, como se pretende ilustrar na Figura 4. A figura procura representar o trajeto da informação sobre os objetivos pelos quatro níveis propostos para a organização, incluindo os processos de criação, seleção e retenção que compõem a dinâmica das sucessivas traduções realizadas sobre eles.

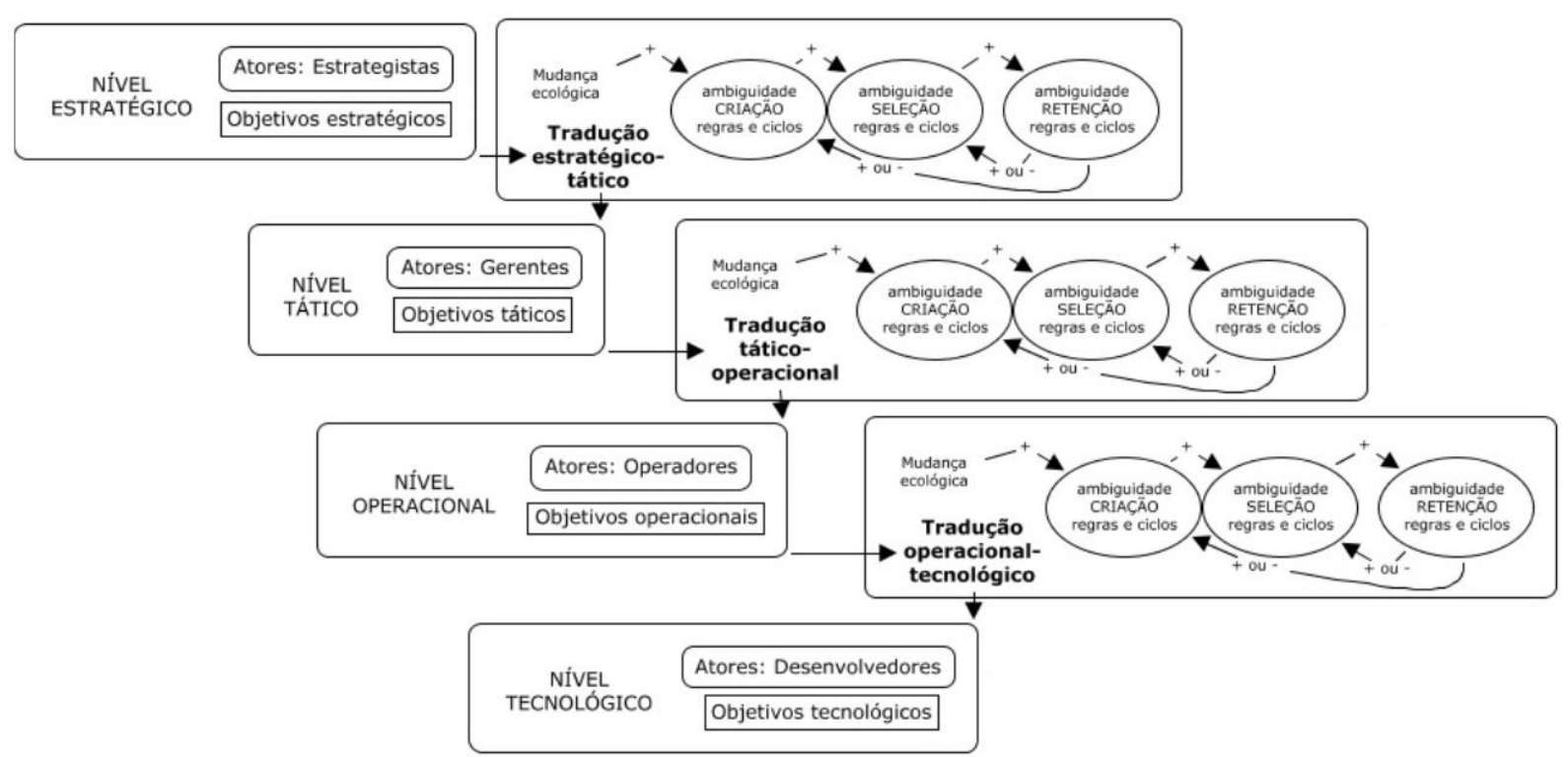

Figura 4. Aproximação do modelo de organização de Weick ao contexto do problema de pesquisa 
A Figura 4 representa conjuntamente o caminho da tradução dos objetivos da organização pelos seus níveis (como na Figura 2), e o modelo de Weick com os processos de formação da organização por criação-seleção-retenção de informações e suas ambiguidades (como na Figura 1). Pretende-se com isso ilustrar a tese de que o modelo ajuda a entender o processo de ambiguação e desambiguação (de alinhamento e desalinhamento) que acontecem na tradução de objetivos do nível estratégico, para o tático, para o operacional e para o nível tecnológico da organização.

\subsection{Aplicação do modelo de Weick ao contexto de pesquisa}

Para descrever como se propõe entender a Figura 5, expõe-se 0 acompanhamento de uma sequência no caminho dos objetivos. A demonstração intercala a exposição de Weick (1973, p.94-95) e o percurso ou caminho dos objetivos em um trecho de uma situação hipotética como a já comentada.

Sendo assim, "Suponha-se a existência de grande ambiguidade, provocada por repentina mudança ecológica, e que essa ambiguidade seja a principal informação que chega ao processo de criação".

Uma mudança ou tendência de mudança (não muito bem definida) na configuração do ambiente organizacional, como o mercado, os clientes, os fornecedores, os concorrentes, seria uma situação em que uma mudança ecológica cria grande ambiguidade no ambiente.

Conforme Weick (1973, p.95), "Supõe-se que as propriedades únicas de qualquer organização possam ser inseridas no modelo, como ciclos ou regras de reunião: as propriedades específicas incluídas nos ciclos seriam as escolhas e comportamentos interligados que ocorrem na organização, e as regras de reunião seriam os critérios usados na organização para compor conjuntos coerentes de ciclos para aplicação à informação recebida pela organização e criada no seu interior".

Exemplos de propriedades incluídas nos ciclos seriam escolhas referentes a quais prioridades estratégicas o grupo de estrategistas definiu prezar para a organização, e, em termos de comportamento, como são as relações de influência e de poder que existem entreos estrategistas no sentido de "de quem são as ideias que prevalecem no final das contas...".

Exemplos de regras de reunião seriam critérios que regem de que forma serão criadas novas ideias de reação ou antecipação à tendência, novo posicionamento ou reposicionamento da organização; com que pessoas serão debatidos aspectos de esclarecimento, por exemplo, das tendências de mudança no mercado; quais critérios serão usados, e como os objetivos serão transmitidos ou informados para os demais níveis da organização.

"A grande ambiguidade na informação leva à ativação de pequeno número de regras de reunião, grande número de ciclos, afastamento de quantidade relativamente grande de ambiguidade e, portanto, menor quantidade de ambiguidade quando a informação atinge o processo de seleção".

As tendências do mercado e do ambiente organizacional REUNA, Belo Horizonte - MG, Brasil, v.23, n.4, p.83-106, Dut. - Dez. 2018 - ISSN 2179-8834 
provocam que os estrategistas realizem um processo de criação e produção de sentido de ideias sobre qual seria a mais adequada reação estratégica organizacional. Utilizam para isso critérios e regras definidos por eles mesmos, cada um para si conforme seu próprio entendimento, e conforme o modo como interpretou a nova informação provinda do ambiente repleta de ambiguidade.

"No entanto, quando a informação chega ao processo de seleção, ainda tem muita ambiguidade, de forma que poucas regras de reunião serão ativadas, muitos ciclos escolhidos e mais afastamento de ambiguidade, o que deixa menos ambiguidade na informação original".

Um processo de seleção pode ser exemplificado por uma reunião de diretoria com debate e apresentação da nova situação, a tendência de mudança de mercado, com a oportunidade de todos explicitarem a ambiguidade que encontraram no cenário da informação que vem do ambiente. Os critérios de seleção são assim expostos pelos estrategistas, e a efetiva seleção de ações a tomar e objetivos a buscar é realizada em conjunto, em ciclos de debate, com exposição das maneiras como cada um produziu o sentido da informação provinda do ambiente, e também com registro das razões, regras e critérios que levaram a tal decisão.

"Ora, se supomos que a maior parte da ambiguidade da informação foi afastada nesse momento (principalmente pelo processo de seleção), quando a informação atinge o processo de retenção haverá ativação de várias regras, seleção de poucos ciclos, afastamento de pouca ambiguidade".

Um processo de retenção da informação na organização pode ser exemplificado pelo registro das decisões dos estrategistas para fins de transmissão delas para o restante da empresa. Neste processo de registro, o afastamento da ambiguidade consiste somente na clareza na descrição das decisões. Se não há preocupação com o esclarecimento dos objetivos para compreensão do próximo nível, a redução da ambiguidade é bem modesta.

Assim, "Conserva-se a maior parte da pequena quantidade de ambiguidade que o item originalmente tinha quando atingiu o processo de retenção".

A informação chega ao próximo nível, neste caso o nível tático, com menos ambigüidade do que tinha ao chegar à organização provinda do ambiente. Transforma-se de tendência de mudanças no ambiente organizacional para objetivos estratégicos a serem implementados. Entretanto, é redigida, registrada, sob a perspectiva do primeiro nível, no caso o estratégico.

"Uma vez que a informação esteja no processo de retenção, é enviada de volta, sob alguma forma, para os processos de seleção e criação".

A informação considerada não-ambígua foi retida e registrada como objetivo estratégico e é enviada adiante para os processos de criação e seleção, realizados agora por atores do nível REUNA, Belo Horizonte - MG, Brasil, v.23, n.4, p.83-I0G, Dut. - Dez. 2018 - ISSN 2179-88834 
seguinte, neste caso o nível tático. Eles realizam um processo semelhante de análise da informação que representa mudança no ambiente, que agora está registrada como objetivos estratégicos. Sua tarefa é formular objetivos táticos com base nos estratégicos.

Estes atores de nível tático, os gerentes, produzem sentido, num processo de criação, sobre a informação nova, procurando afastar a ambiguidade da informação sobre objetivos estratégicos que Ihes foi enviada pelo nível anterior. Também estabelecem critérios para a tomada de decisão sobre as ações a serem efetivadas quanto à definição ou redefinição dos objetivos táticos, num processo de seleção, que afasta mais ambiguidade. Além disso, registram os novos objetivos para transmissão ao próximo nível, num processo de retenção.

"Suponhamos que o ator decida reenviar a informação de volta para o sistema como uma informação ambígua. Isso significa que trata o item não ambíguo conservado como se fosse ambíguo para ações futuras; em outras palavras, decide interpretá-lo de maneira mais diversa. Ativa poucas regras de reunião para lidar com o item; muitos ciclos são escolhidos e aplicados ao item; finalmente, afasta-se grande parte da ambiguidade do item".

A hipótese é que a informação retida pelo nível anterior (os novos objetivos estratégicos) chega ao nível tático com tanta ambiguidade, que não permite decisões bem fundamentadas quanto à definição das ações futuras, ou seja, dos objetivos táticos (o que pode ser considerado bastante comum). Os atores gerentes percebem que é possível interpretar de maneiras diversas a informação recebida; então poderiam (e deveriam!) realizar a retroconsulta aos estrategistas para um melhor esclarecimento desses objetivos.

Em outras palavras, em vez de ativar regras de tratamento da informação no nível tático (e já sair fazendo escolhas e definições), o gerente pode escolher realizar um novo ciclo de tratamento da informação, retornando aos processos de criação, seleção e retenção do nível anterior. Assim, afasta uma quantidade suficiente de ambiguidade para compreender com mais segurança tais objetivos e efetuar o ciclo de criação, seleção e retenção no seu nível.

Mas "Suponhamos, além disso, que o ator encaminhe a informação diretamente ao processo de criação e seleção. Isso significa que trata o item não ambíguo retido como se fosse não ambíguo para futuras escolhas; ativa muitas regras, reúne poucos ciclos, afasta pouca ambiguidade".

A hipótese agora é que o ator gerente não realize a retroconsulta nem o consequente retorno do processo à criação e seleção realizadas no nível anterior. Ele não refaz o ciclo, e assim não melhora o entendimento da informação recebida, mas ativa as regras de tratamento da informação no seu nível. Assim, o conteúdo é criado, selecionado e retido de acordo com suas crenças, seus critérios e seu próprio entendimento quanto à 
informação retida pelo nível estratégico. A informação é então encaminhada para o nível operacional, mas contém ainda grande parte da ambiguidade com que foi disponibilizada para 0 nível tático.

Com essa visão geral, vale lembrar o que Weick explica: "Cada ciclo comportamental interligado pode afastar certa ambiguidade, mas só quando vários ciclos diferentes são aplicados à informação é que um grau suficiente de certeza é conseguido para que seja possível ação não ambígua".

Pode-se dizer que as fases anteriores (e suas opções de escolha) da situação hipotética aqui descrita são repetidas nos demais processos de tradução. Os processos de criação, seleção e retenção de informação ocorrem do mesmo modo que a tradução aqui descrita dos objetivos estratégicos-táticos, porém com atores, critérios e regras diferentes conforme o nível nas traduções tático-operacional e operacional-tecnológico até os sistemas de informação.

\section{Discussão da aplicação do modelo ao contexto de pesquisa}

Pode-se dizer que a concepção sistêmica da organização se concilia com a ideia de Weick (1973) da organização como processo. Rummler e Brache também sustentam ( $p .14$ ) que a abordagem de sistemas descreve qualquer organização. $E$ não é demais reafirmar a visão de Weick sobre a criação-seleção-retenção que formam a organização (p.90): "Esses processos são comportamentos interligados, relacionados e que constituem um sistema".

Em resumo, Weick (1973, p.1) parte da suposição de que "existem processos que criam, conservam e dissolvem coletividades sociais, que tais processos constituem o trabalho de organizar, e que as maneiras pelas quais tais processos são continuamente executados são a organização". E segundo o modelo, a organização é um coletivo cuja questão central são as incertezas internas causadas pelas pessoas que as formam, e "a criação de sentido e a seleção de ações são parte dos processos de decisão em um sistema interpretativo" (DAFT e WEICK, 2005).

Sobre o modelo de organização, Weick diz que "embora seja apresentado em nível abstrato, cria uma forma específica de pensar quando é aplicado a distinções e conceitos concretos" (p.105). O modelo propõe que, para compreender mais a respeito de uma organização, uma possibilidade seria procurar "comportamentos entrelaçados que estão imersos em processos condicionalmente relacionados". Essas são as relações intersubjetivas que aqui se intenta explorar no contexto da implantação de estratégias em processos de negócio e, por fim, em sistemas de informação.

Segundo o modelo, "as ações estão associadas à criação, e as escolhas estão associadas à seleção; ambas estão nos ciclos escolhidos, que são formados por comportamentos interestruturados. No caso de criação, os ciclos adequados para esse processo referem-se a fazer, agir e realizar. No caso de seleção, referem-se a escolhas das ações anteriores que devem ser repetidas, reconhecidas e consideradas como experiência benéfica. [...] $\mathrm{O}$ processo de retenção também reduz parte da 
ambiguidade, pois, no registro, integra itens novos em itens anteriormente conservados" (p.95).

"As relações básicas entre os processos são relações de controle, e representam as formas pelas quais os processos são determinados pelo estado das informações recebidas. [...] Quando se obtém informação a respeito do grau de ambiguidade em alguma informação importante recebida, pode-se saber regras que serão ativadas, ciclos que serão selecionados, a quantidade de ambiguidade que será afastada, a natureza da informação transmitida a processos posteriores e o destino dessa informação conforme for processada pelos processos subsequentes. [...] Quando se obtém informação a respeito da maneira de usar (enviar de volta ou enviar adiante) o conteúdo conservado, pode-se especificar a natureza das relações causais do envio da retenção para criação".

Como exemplo, pode-se citar: "Sempre que um ator pergunta o que é que deve fazer a partir daquilo que sabe, na realidade está procurando saber se deve continuar a ser orientado pelo estado da informação na retenção, ou se deve contrabalançar esse estado. (p.95) Faz isso quando decide retroenviar o fluxo do processo à criação e à seleção do nível anterior se há muita ambiguidade na informação no processo de retenção; porém, se considera que a informação está não-ambígua, decide enviar o fluxo do processo adiante para a criação e seleção do nível seguinte" (p.92).

Aí está a contribuição do modelo para a compreensão do processo de tradução dos objetivos da organização no caminho que percorrem entre os seus níveis: conforme o grau de ambiguidade e a maneira de usar a informação recebida. Tais elementos podem definir a "fidelidade da tradução" dos objetivos de um nível para outro, objetivo das técnicas de métodos de alinhamento estratégico; e ajudar a prever (até prevenir) a ocorrência do efeito "telefone-sem-fio" no caminho dos objetivos.

\section{Considerações finais}

Este estudo teve como objetivo investigar a contribuição que uma determinada teoria poderia trazer para permitir dar um significado, uma explicação, uma compreensão, uma interpretação a determinados fatos investigados, para abrir perspectivas para futuras pesquisas. A teoria resgatada refere-se ao modelo de organização como processos de criação, seleção e retenção de informações e suas ambiguidades proposto por Karl Weick (1973), e os fatos referem-se ao processo de (des)alinhamento no caminho da tradução dos objetivos estratégicos em processos de negócio, e em sua implantação em sistemas de informação de uma organização.

O modelo e o contexto de pesquisa foram apresentados e relacionados entre si numa tentativa de aproximação, e foram identificadas contribuições que a aplicação do modelo de Weick ao contexto da tradução de objetivos da organização pode trazer para a compreensão desse processo. Talvez possa ser considerada como uma limitação da pesquisa o uso exclusivo de um só modelo. Mas o modelo ofereceu potenciais explicações para as relações que regem o modo de tomada de decisão quanto ao afastamento de ambiguidade da informação em cada nível da organização, o que permitiu compreender os motivos para a decisão de não-afastamento da ambiguidade, que teria potencial para causar desalinhamento na tradução de objetivos ao longo dos níveis organizacionais. 
Também se conclui que as organizações podem ser entendidas como sistemas sociais abertos que processam informações, sujeitas à incerteza para basear a sua tomada de decisão, interna e externamente, podendo ser interpretadas como produtos da interação social. Uma linha de pesquisas futuras suscitadas pelo estudo diz respeito ao efeito da disseminação da cultura organizacional como habilitadora do compartilhamento de sentidos nas traduções. Outra linha de pesquisa a ser aprofundada teria foco nas interações sociais e nas motivações individuais dos atores e na sua produção de sentido sobre decisões quanto à manutenção ou afastamento da ambiguidade dos objetivos. Com essas bases, podem ser esboçadas proposições para desenvolvimento posterior:

- O registro da ambiguidade da informação recebida pelos atores de um nível da organização auxilia o processo de seleção de ações a serem tomadas para a composição dos objetivos para esse nível.

- O processo coletivo interativo de seleção das informações que vão compor os objetivos pode afastar mais ambiguidade do que o processo de seleção de informações realizado individualmente.

- O registro dos critérios de seleção de ações a serem tomadas para a composição dos objetivos de um nível da organização reduz a ambiguidade na tradução dos objetivos para o nível seguinte.

- A prática de retroconsultas em relação ao nível anterior emissor dessas informações sobre objetivos auxilia o compartilhamento de sentido sobre os objetivos a serem criados no nível receptor.

- O processo de retenção tem potencial para afastar mais ambiguidade quando efetivado com uso de técnicas gerenciais de representação de conhecimento na forma de objetivos, processos e medidas.

Para manter a fidelidade na tradução dos objetivos estratégicos em objetivos táticos, operacionais e tecnológicos, uma contribuição gerencial deste estudo pode ser a recomendação da prática da retroconsulta para o esclarecimento e desambiguação das informações transmitidas, desde o nível estratégico até cada outro nível. Rummler e Brache (1994) afirmam que, "apesar de muitos diretores serem talentosos e esforçados, eles não conseguem implementar objetivos estratégicos sozinhos; uma etapa muito importante é a comunicação e a compreensão da estratégia pelas pessoas, e uma contribuição-chave é dada pelos gerentes que administram sistemas e implementam objetivos".

Por outro lado, Weick diz que "a missão da teoria não é gerar contribuições que possam ser usadas nas atividades diárias de direção de uma organização, pois a utilidade teórica não é definida pragmaticamente" (p.19). Então, como contribuição teórica, o modelo de Weick (1973, p.97) oferece uma ideia da maneira pela qual o "pensamento tradicional" sobre implantação de estratégias pode ser reinterpretado. Espera-se que o estudo possa contribuir para uma melhor compreensão do processo de tradução de objetivos na implantação de uma estratégia em processos de negócio, auxiliando na redução da lacuna de conhecimento existente. 


\section{Referências}

ADESOLA, S.; BAINES, T. Developing and evaluating a methodology for business process improvement. Business Process Management Journal. v.11, n.1, 2005, p.37-46.

ANANTATMULA, V.S.; RAD, P.F. Role of Organizational Project Management Maturity Factors on Project Success. Engineering Management Journal, v.30, n.3, 2018, pp.165-178, DOI: $\underline{10.1080 / 10429247.2018 .1458208}$

ANDERSON, M.H. How can we know what we think until we see what we said? A citation and citation context analysis of Karl Weick's The Social Psychology of Organizing. Organization Studies, v.27, n.11, 2006, p.1675-1692.

ANTONY, J.; GUPTA, S. Top ten reasons for process improvement project failures, International Journal of Lean Six Sigma, 2018. https://doi.org/10.1108/IJLSS-11$\underline{2017-0130}$

BELTH, M. La educación como disciplina científica. Buenos Aires: El Ateneo, 1971.

BJORVATN, T.; WALD, A. Project complexity and team-level absorptive capacity as drivers of project management performance. International Journal of Project Management, v.36, n.6, August 2018, pp.876-888. https://doi.org/10.1016/j.ijproman.2018.05.003

BRODBECK, A.F.; HOPPEN, N. Alinhamento Estratégico entre os Planos de Negócio e de T.I. Revista de Administração Contemporânea, v.7, n.3, jul-set. 2003, p.9-33.

BYGBALLE, L.; SWÄRD, A. Collaborative project delivery models and the role of routines in partnering. Project Management Journal, 2019. https://doi.org/10.1177/8756972818820213

COBAITO, F.C. Gerenciamento da comunicação em projetos: uma análise bibliométrica da produção científica brasileira. Revista de Administração e Contabilidade (ReAC). v.10, n.2, maio/ago. 2018. pp.50-63. http://www.reacfat.com.br/index.php/reac/article/view/146

CYGANCZUK, M.S.; MENDES, R. Jr.; PÉCORA, J.E. Jr. Percepções dos gerentes de projeto em relação às falhas e barreiras de comunicação. Gestão da Produção, $\begin{array}{llllll}\text { Operações e Sistemas } & \text { (GEPROS), } & \text { v.13, } & \text { n.1, } & \end{array}$ https://doi.org/10.15675/gepros.v13i1.1992

DAFT, R.; WEICK, K.E. Por um modelo de organização concebido como sistema interpretativo. Revista de Administração de Empresas, v.45, n.4, 2005, p.73-86.

DEBEVOISE, T. Business Process Management with a Business Rules Approach: implementing the SOA. Business Knowledge Architects, Canada, 2007.

DONESTES. Don Estes Consulting. Technical Issues presented as Business Issues. 2015. https://www.donestes.com/business-rules/businessanalysis-4/ Acesso: 29 mar. 2018. 
GARCÍA-CARBONELL, N.; MARTÍN-ALCÁZAR, F.; SANCHEZ-GARDEY, G. Determinants of building consistent human resources management systems: A focus on internal communication. International Journal of Manpower, v.39, n.3, 2018, pp.354-377. https://doi.org/10.1108/lJM-06-2016-0140

GHALIMI, I. BPM e Workflow. 2007. Disponível em: www.cryo.com.br. Acesso: 2 abr. 2018.

GONÇALVES, J. As empresas são grandes coleções de processos. Revista de Administração de Empresas. São Paulo, v.40, n.1, jan.-mar.2000, p.6-19.

HREBINIAK, L.G. Making Strategy Work: Leading Effective Execution and Change. 2.ed. New Jersey: Wharton School Publishing, 2013.

ISHAK, A.W.; WILLIAMS, E.A. A dynamic model of organizational resilience: adaptive and anchored approaches, Corporate Communications: An International Journal, v.23, n.2, 2018, pp.180-196, https://doi.org/10.1108/CClJ-04-2017-0037

JIANG, J.; KLEIN, G.; FERNANDEZ, W.From project management to program management: an invitation to investigate programs where IT plays a significant role. Journal of the Association for Information Systems, v.19, n.1, 2018, pp.40-57. doi: 10.17705/1jais.00480

LIEBEL, G.; TICHY, M.; KNAUSS, E.; LJUNGKRANTZ, O.; STIEGLBAUER, G. Organization and communication problems in automotive requirements engineering. Requirements Engineering, v.23, n.1, March 2018, pp.145-167. https://doi.org/10.1007/s00766-016-0261-7

MALANOVICZ, A.V.; BRODBECK, A.F. Entendimento Compartilhado de Demandas em Projetos de Desenvolvimento de Sistemas: uma Análise de Episódios Autoetnográficos segundo o Modelo de Organização de Weick. Revista Eletrônica Gestão e Serviços, v.8, pp.1919-1964, 2017. dx.doi.org/10.15603/21777284/regs.v8n1p1919-1964

MANATA, B.; MILLER, V.; MOLLAOGLU, S.; GARCIA, A.J. Measuring Key Communication Behaviors in Integrated Project Delivery Teams. Journal of Management in Engineering, v.34, n.4, July 2018. https://doi.org/10.1061/(ASCE)ME.1943-5479.0000622

MEDEIROS, H.G.C. As Dificuldades e Barreiras Enfrentadas na Gestão de Pessoas. São Caetano do Sul/SP: LURA, 2016.

MILES, R.; SNOW, C.; MEYER, A.; COLEMAN, JR., H. Organizational strategy, structure, and process. The Academy of Management Review, v.3, jul.1978.

NAHYAN, M.T.A.; SOHAL, A.; HAWAS, Y.; FILDES, B. Communication, coordination, decision-making and knowledge-sharing: a case study in construction management. Journal of Knowledge Management, 2019. https://doi.org/10.1108/JKM-08-2018$\underline{0503}$ 
NOGUERA, I.; GUERRERO-ROLDÁN, A.-E.; MASÓ, R. Collaborative agile learning in online environments: Strategies for improving team regulation and project management. Computers \& Education, 116, January 2018, pp.110-129. https://doi.org/10.1016/j.compedu.2017.09.008

OLIVEIRA, G.F.; RABECHINI Jr., R. Stakeholder management influence on trust in a project: a quantitative study. International Journal of Project Management, v.37, n.1, January 2019, pp.131-144. https://doi.org/10.1016/j.ijproman.2018.11.001

ORGANIZATION STUDIES. Making Sense of Organizing: in Honour of Karl Weick. v.27, nov.2006, p.1573-1736.

OSWALD, D.; WADE, F.; SHERRATT, F.; SMITH, S.D. Communicating health and safety on a multinational construction project: challenge \& strategy. Journal of Construction Engineering and Management, v.145, n.4, 2019. https://doi.org/10.1061/(ASCE)C0.1943-7862.0001634

PERONARD, J.-P.; BRIX, J. Organizing for inter-organizational learning in service networks. The Learning Organization, 2018. https://doi.org/10.1108/TLO-08-2018$\underline{0137}$

PIVEC, M.; MACEK, A. Employment background influence on social media usage in the field of European project management and communication. Journal of Business Research, v.94, January 2019, pp.280-289. https://doi.org/10.1016/j.jbusres.2018.03.021

RAMOS-RODRIGUEZ, A.; RUIZ-NAVARRO, J. Changes in intellectual structure of strategic management research. Strategic Management Journal, v.25, n.10, 2004, p.981-1004.

RUMMLER, G.; BRACHE, A. Improving Performance. São Paulo: Makron, 1994.

SCHLEGEL, E.F.M.; McLEOD, K.B.D.; SELFRIDGE, N.J. Practical Tips for Successful Implementation of Educational Innovations: Project Management Tools for Health Professional Educators. MedEdPublish, 2018. https://doi.org/10.15694/mep.2018.0000105.1

SMALLA, A.; WAINWRIGHT, D. Privacy and security of electronic patient records: Tailoring multimethodology to explore the socio-political problems associated with Role Based Access Control systems. European Journal of Operational Research, v.265, n.1, Feb.2018, pp.344-360. https://doi.org/10.1016/j.ejor.2017.07.041

STERREN, M.V.D.; GOLDING, B. Agile modeling: Current practice, fad or future? Hydrology and Water Resources Symposium (HWRS 2018). Melbourne, Australia, 2018, pp.873-883. https://search.informit.com.au/documentSummary; $d n=127175733653801$;res=IELEN $\underline{\mathrm{Gb}}$ 
TONOLLI JÚNIOR, E.J.; BRODBECK, A.F.; COSTA, C. Análise das relações dos elementos de alinhamento estratégico entre negócio e tecnologia da informação com o processo de desenvolvimento de produto. Revista de Administração Mackenzie, São Paulo/SP, v.13, n.2, mar.-abr.2012, p.135-170.

VANHANEM, J.; LEHTINEN, T.O.A.; LASSENIUS, C. Software engineering problems and their relationship to perceived learning and customer satisfaction on a software capstone project. Journal of Systems and Software. v.137, March 2018, pp. 50-66. https://doi.org/10.1016/j.jss.2017.11.021

WERNHAM, R. Obstacles to Strategy Implementation in a Nationalized Industry. Journal of Management Studies, v.22, n.6, 1985, p.632-648.

WEICK, K.E. A Psicologia Social da Organização. São Paulo: Edgard Blucher, 1973.

ZUO, J.;ZHAO, X.; NGUYEN, Q.; TONY, M.; GAO, S. Soft skills of construction project management professionals and project success factors. Engineering Construction \& Architectural Management, v.25, n.4, May 2018. DOI: 10.1108/ECAM-01-2016$\underline{0016}$ 